\title{
Introduction
}

\section{Constraint-Induced Movement therapy: Answers and questions after two decades of research}

\author{
Edward Taub $^{\mathrm{a}, \mathrm{c}, *}$ and Gitendra Uswatte ${ }^{\mathrm{a}, \mathrm{b}}$ \\ ${ }^{a}$ Department of Psychology, School of Social \& Behavioral Sciences, University of Alabama at Birmingham, AL, \\ USA \\ ${ }^{\mathrm{b}}$ Department of Physical Therapy, School of Health Related Professions, University of Alabama at Birmingham, \\ AL, USA \\ ${ }^{\mathrm{c}}$ Research Service, Birmingham Veterans Affairs Medical Center, Birmingham, AL, USA
}

\begin{abstract}
Constraint-Induced Movement therapy or CI therapy is a behavioral approach to neurorehabilitation based on a program of neuroscience experiments conducted with deafferented monkeys. Over the last 20 years, a large body of evidence has accumulated to support the efficacy of CI therapy for rehabilitating hemiparetic arm use in individuals with chronic stroke. Given the persuasive evidence for its efficacy to date, other research questions have risen to the forefront. How cost-effective is CI therapy? What are optimal training and other treatment parameters? What patient characteristics moderate the effects of CI therapy? The papers gathered in this special issue address many of these topics.
\end{abstract}

Constraint-Induced Movement therapy, also known as CI therapy [11], is a behavioral approach to neurorehabilitation derived from basic neuroscience $[9,13]$. Specifically, the approach is based on a program of research conducted by one of us (E. Taub) with monkeys after deafferentation of one forelimb that showed that nonuse of the deafferented forelimb is learned and can be overcome by the application of simple behavioral techniques (e.g., shaping $[6,10]$ of impaired extremity use) [8]. The treatment for humans after neurological injury has three components: (a) repetitive, taskoriented training of the impaired extremity or function following shaping principles for several hours a day for 10 or 15 consecutive weekdays (depending on the severity of the initial deficit); (b) constraining patients

*Address for correspondence: Edward Taub, Ph.D., University Professor of Psychology, University of Alabama at Birmingham, 1530 3rd Ave S., CPM712, Birmingham, AL 35294, USA. Tel.: +1 205934 2471; Fax: +1 205975 6140; E-mail: etaub@uab.edu. to use the impaired extremity or function during waking hours over the course of treatment, sometimes by restraining the unimpaired extremity; and (c) applying a package of behavioral methods designed to transfer gains made in the clinical setting to the real-world [14].

Over the last 20 years, a large body of evidence has accumulated to support the efficacy of CI therapy for hemiparesis subsequent to chronic stroke (i.e., > 1-year post-injury; e.g., see reviews by Taub and Uswatte [12], Sterr and Saunders in this issue). Evidence for efficacy includes results from: the initial small, randomized controlled trial (RCT) of CI therapy in individuals with mild-to-moderate upper-extremity hemiparesis secondary to chronic stroke [11]; a larger, placebocontrolled trial in individuals of the same chronicity and level of impairment [14]; a large, multi-site RCT in individuals with mild-to-moderate and moderate upperextremity hemiparesis subsequent to subacute stroke (i.e., 3-9 months post-stroke) [18]. Positive findings regarding CI therapy after chronic stroke have also been 
obtained in several studies employing within-subjects control procedures (e.g. $[1,4,7]$ ) and numerous case studies (reviewed in [12]). Moreover, the most recent post-stroke clinical care guidelines [2] describe CI therapy as an intervention that has evidence of benefit for stroke survivors with mild-to-moderate upperextremity hemiparesis.

Although virtually all of the CI therapy papers in the chronic stroke literature we know of report positive results [12], the range of effect sizes described is wide. A possible reason for this variation in outcomes is that some researchers used only one or two instead of all three components of the CI therapy treatment package. For example, studies employing only restraint of the unimpaired extremity (known as "forced-use" therapy; e.g. [17]) typically have much smaller effect sizes than those employing all three CI therapy components. Another possible explanation is that some researchers did not implement the CI therapy protocol properly. For example, van der Lee and co-workers [16] provided training of hemiparetic use in a group format using "housekeeping activities, handicrafts, and games [16]," which is likely to have resulted in much less intense training than is desirable for CI therapy [14]. To help address these problems, our laboratory has started holding semi-annual training workshops and is preparing a training manual for publication.

Given the robust evidence overall for the efficacy of CI therapy at this date, other research questions have risen to the forefront. How cost-effective is CI therapy? What are optimal training and other treatment parameters? What patient characteristics moderate the effects of CI therapy? In addition, an intervention with persuasive evidence of efficacy permits researchers to test questions of wide import for neurorehabilitation such as what are the effects of physical rehabilitation on the brain (e.g. [3]) and what pharmacological agents enhance the effects of physical rehabilitation (e.g. [5], Nadeau and $\mathrm{Wu}$ in this issue).

The papers gathered in this special issue address many of these topics. Mennemeyer, Taub, Uswatte, and Pearson report on return-to-work of family caregivers of CI therapy patients. Sterr and Saunders review the CI therapy literature with a focus on issues salient to the provision of CI therapy in clinical settings, such as the distribution and amount of training. Uswatte, Taub, Morris, Barman, and Crago present a set of preliminary studies examining the effect of type of training (i.e., shaping vs. repetitive task practice) and restraint of the unimpaired arm on CI therapy outcome. In separate papers, (a) Mark, Woods, Mennemeier, Abbas, and Taub and (b) Morris, Shaw, Mark, Uswatte, Barman, and Taub report on neuropsychological characteristics that moderate the effect of CI therapy in stroke and traumatic brain injury survivors, respectively. Bowman, Taub, Uswatte, Delgado, Bryson, Morris, McKay, and Mark, extending previous work from our laboratory examining the efficacy of CI therapy in patients with lower levels of impaired arm function than in the original studies [15], present a case report on a stroke survivor with virtually no active movement in the wrist and fingers of the hemiparetic arm. Nadeau and Wu discuss how CI therapy can be used as a "behavioral engine" to test pharmacological agents that might enhance the effect of physical rehabilitation techniques.

We thank the Editorial Board of NeuroRehabilitation for providing a forum in which to present this work, and hope that the readers of NeuroRehabilitation will find the papers gathered of import to their clinical practice and research.

\section{Acknowledgments}

This research was supported by Grant HD34273 from the National Institutes of Health and Grant B95975 from the Veterans Affairs Administration.

\section{References}

[1] C. Dettmers, U. Teske, F. Hamzei, G. Uswatte, E. Taub and C. Weiller, Distributed form of Constraint-Induced Movement therapy improves functional outcome and quality of life after stroke, Archives of Physical Medicine and Rehabilitation $\mathbf{8 6}$ (2005), 204-209.

[2] P.W. Duncan, R. Zorowitz, B. Bates, J.Y. Choi, J.J. Glasberg, G.D. Graham, R.C. Katz, K. Lamberty and D. Reker, Management of adult rehabilitation care: a clinical practice guideline, Stroke 36 (2005), e100-e143.

[3] J. Liepert, H. Bauder, W.H.R. Miltner, E. Taub and C. Weiller, Treatment-induced cortical reorganization after stroke in humans, Stroke 31 (2000), 1210-1216.

[4] W.H.R. Miltner, H. Bauder, M. Sommer, C. Dettmers and E. Taub, Effects of Constraint-Induced Movement therapy on chronic stroke patients: a replication, Stroke 30 (1999), 586592.

[5] S.E. Nadeau, A.L. Behrman, S.E. Davis, K. Reid, S.S. Wu, B.S. Stidham, K. Helms and L.J. Gonzalez Rothi, Donepezil as a adjuvant to constraint-induced therapy for upper-limb dysfunction after stroke: an exploratory randomized clinicl trial, Journal of Rehabilitation Research and Development 41 (2004), 525-534.

[6] B.F. Skinner, The Technology of Teaching, Appleton-CenturyCrofts, New York, 1968. 
[7] A. Sterr, T. Elbert, I. Berthold, S. Kölbel, B. Rockstroh and E. Taub, Longer versus shorter daily Constraint-Induced Movement therapy of chronic hemiparesis: an exploratory study, Archives of Physical Medicine and Rehabilitation 83 (2002), 1374-1377.

[8] E. Taub, Movement in nonhuman primates deprived of somatosensory feedback, in: Exercise and Sports Science Reviews, Journal Publishing Affiliates, Santa Barbara, 1977, pp. 335-374.

[9] E. Taub, Somatosensory deafferentation research with monkeys: implications for rehabilitation medicine, in: Behavioral Psychology in Rehabilitation Medicine: Clinical Applications, L.P. Ince, ed., Williams \& Wilkins, New York, 1980, pp. 371-401.

[10] E. Taub, L. Burgio, N.E. Miller, E.W. Cook, III, T. Groomes, S. DeLuca and J. Crago, An operant approach to overcoming learned nonuse after CNS damage in monkeys and man: the role of shaping, Journal of the Experimental Analysis of Behavior 61 (1994), 281-293.

[11] E. Taub, N.E. Miller, T.A. Novack, E.W. Cook, III, W.C. Fleming, C.S. Nepomuceno, J.S. Connell and J.E. Crago, Technique to improve chronic motor deficit after stroke, Archives of Physical Medicine and Rehabilitation 74 (1993), 347-354.

[12] E. Taub and G. Uswatte, CI therapy: bridging from the primate laboratory to the stroke rehabilitation laboratory, Journal of Rehabilitation Medicine Suppl 41 (2003), 34-40.
[13] E. Taub, G. Uswatte and T. Elbert, New treatments in neurorehabilitation founded on basic research, Nature Reviews Neuroscience 3 (2002), 228-236.

[14] E. Taub, G. Uswatte, D.K. King, D. Morris, J. Crago and A. Chatterjee, A placebo controlled trial of Constraint-Induced Movement therapy for upper extremity after stroke, Stroke $\mathbf{3 7}$ (2006), 1045-1049.

[15] E. Taub, G. Uswatte and R. Pidikiti, Constraint-Induced Movement therapy: a new family of techniques with broad application to physical rehabilitation - a clinical review, Journal of Rehabilitation Research and Development 36 (1999), 237 251.

[16] J.H. van der Lee, R.C. Wagenaar, G.J. Lankhorst, T.W. Vogelaar, W.L. Deville and L.M. Bouter, Forced use of the upper extremity in chronic stroke patients: results from a single-blind randomized clinical trial, Stroke 30 (1999), 2369-2375.

[17] S.L. Wolf, D.E. Lecraw, L.A. Barton and B.B. Jann, Forced use of hemiplegic upper extremities to reverse the effect of learned nonuse among chronic stroke and head-injured patients, Experimental Neurology 104 (1989), 125-132.

[18] S.L. Wolf, C. Winstein, J.P. Miller, E. Taub, G. Uswatte, D. Morris, C. Giuliani, D. Good, K. Light and D. Nichols-Larsen, The Extremity Constraint Induced Therapy Evaluation (EXCITE) trial for patients with sub-acute stroke, in: Plenary Session III Late Breaking Science Abstracts, International Stroke Conference, Kissimmee, FL, February 2006. 